\title{
Correction to: Highlights from 2017: impactful topics published in the Annals of Nuclear Medicine
}

\author{
Andrea Farolfi ${ }^{1}$ (D) Pietro Ghedini ${ }^{1} \cdot$ Stefano Fanti ${ }^{1}$
}

Published online: 12 October 2018

(C) Springer-Verlag GmbH Germany, part of Springer Nature 2018

\section{Correction to: European Journal of Nuclear Medicine and Molecular Imaging https://doi.org/10.1007/s00259-018-4169-y}

The author names in the original version of this article were inversed. Correct author names were reflected here.

The original article has been corrected.

The online version of the original article can be found at https://doi.org/ 10.1007/s00259-018-4169-y

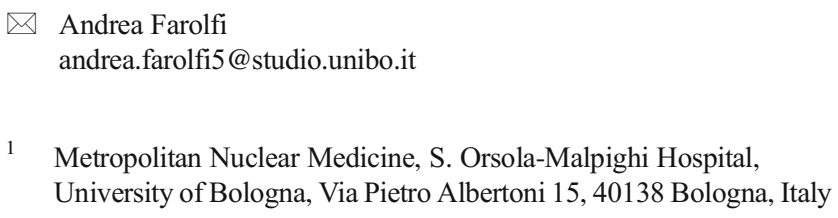

